\title{
ANALISIS STRATEGI BISNIS PADA PERUSAHAAN INSPEKSI DALAM INDUSTRI JASA INSPEKSI TEKNIS DI INDONESIA
}

\author{
Mayella Lusiana Gunawan \\ Program Studi Magister Manajemen, Universitas Tarumanagara \\ mayella.lusiana@gmail.com
}

\begin{abstract}
The objectives of the study are: (a) to identify internal and external factors affecting Inspection Company in the technical inspection services industry; (b) to find the suitable and effective business strategy for Inspection Company in order to increasing sales performance in the strong competition environment. Data collection techniques required in this study is using primary data (information and data) (case studies and literature). The first step to be done in this research is the input stage, followed by the Matching Stage, and the last stage is the decision analysis. The Result of the research are: (a) recommended strategy for Inspection Company is product development; (b) the second recommendation of the business strategy is horizontal integration.
\end{abstract}

Keywords: business strategy, product development, horizontal integration

\section{PENDAHULUAN}

Era globalisasi telah mendorong dunia bisnis menjadi semakin kompetitif dan membuat perusahaan berfokus pada kemampuannya untuk bersaing dan bertahan di dalam dunia bisnis. Perusahaan dituntut untuk mampu menciptakan inovasi baru yang mampu memenangkan persaingan di dunia global.

Salah satu industri yang akan penulis teliti adalah industri jasa inspeksi teknis dalam sektor Minyak dan Gas Bumi (Migas). Krisis harga minyak yang melanda dunia akhir-akhir ini menyebabkan menurunnya kegiatan eksplorasi migas dan menurunnya aktivitas yang diterima oleh perusahaan-perusahaan yang melakukan jasa inspeksi teknis. Beberapa perusahaan-perusahaan jasa inspeksi teknis mulai mencari cara dan alternatif untuk menghadapi kondisi yang ada. Migas sebagai lembaga pembina dan pengawas usaha penunjang perusahaan tersebut dapat berperan dan membatu mencari solusi agar bisa tetap bertahan dan tumbuh di dalam industrinya.

Persaingan yang terjadi dalam industri jasa inspeksi teknis tersebut termasuk persaingan yang terjadi dengan sesama perusahaan lokal maupun perusahaan lokal dengan perusahaan asing, seperti SGS, DNV, Bureau Veritas, dan sebagainya. Persaingan juga disebabkan oleh faktor harga, perhitungan tingkat kandungan dalam negeri (TKDN), pengalaman di masa lalu, maupun kompetensi dari sisi personel dan teknologi yang digunakan.

Berdasarkan latar belakang di atas, maka penulis tertarik untuk melakukan penelitian yang berjudul "Analisis Strategi Bisnis pada Perusahaan Inspeksi dalam Industri Jasa Inspeksi Teknis di Indonesia." Tujuan dari penelitian ini adalah untuk mengidentifikasi (1) faktor-faktor internal dan eksternal apa saja yang mempengaruhi Perusahaan Inspeksi dalam industri jasa inspeksi teknis; (2) mengetahui strategi bisnis yang tepat dan efektif agar kinerja penjualan Perusahaan Inspeksi meningkat dalam menghadapi persaingan yang ketat. Hasil penelitian diharapkan bahan masukan dan pertimbangan bagi perusahaan untuk menyusun rencana dan kebijakan di masa yang akan datang. Dan bagaimana merumuskan strategi yang tepat dalam rangka menciptakan keunggulan kompetitif perusahaan. 


\section{KAJIAN TEORI}

Manajemen strategis didefinisikan sebagai suatu rangkaian keputusan dan tindakan yang menghasilkan formulasi dan implementasi rencana untuk mencapai tujuan perusahaan (Pearce and Robinson, 2013). Menurut David \& Wheelen (2003) manajemen strategi adalah serangkaian keputusan dan tindakan manajerial yang menentukan kinerja perusahaan dalam jangka panjang. Sedangkan David (2011) mendefinisikan manajemen strategi sebagai ilmu tentang perumusan, pelaksanaan dan evaluasi keputusan-keputusan lintas fungsi yang memungkinkan organisasi mencapai tujuannya. Menurut Rangkuti (2008), strategi merupakan alat untuk mencapai tujuan perusahaan dalam kaitannya dengan tujuan jangka panjang, program tindak lanjut, serta prioritas alokasi sumber daya. Strategi adalah pilihan untuk melakukan aktivitas dengan cara yang berbeda dari pesaingnya.

Dengan demikian dapat disimpulkan bahwa inti dari manajemen strategi adalah memenangkan persaingan, oleh karena itu maka, perusahaan harus senantiasa menganalisis dan memperbaiki manajemen strategi perusahaan agar lebih baik dari perusahaan pesaing.

Lingkungan Eksternal. Menurut Pearce dan Robinson (1997) yang dimaksud dengan lingkungan eksternal perusahaan adalah faktor-faktor di luar kendali perusahaan yang dapat mempengaruhi pilihan arah dan tindakan, struktur organisasi, dan proses internal perusahaan. Faktor-faktor tersebut dapat dibagi menjadi tiga sub kategori yang saling terkait, yaitu faktorfaktor dalam lingkungan jauh, faktor-faktor dalam lingkungan. Pearce dan Robinson (1997) membagi lingkungan eksternal menjadi tiga yaitu lingkungan jauh, lingkungan industri, dan lingkungan operasional.

Lingkungan jauh adalah faktor-faktor yang bersumber dari luar dan biasanya tidak berhubungan dengan situasi operasional suatu perusahaan tertentu (Pearce dan Robinson, 1997). Lingkungan jauh memberikan kesempatan besar bagi organisasi untuk maju, sekaligus menjadi hambatan maupun ancaman (Umar, 2001). Faktor-faktor yang termasuk dalam lingkungan jauh adalah faktor politik, ekonomi, sosial, dan teknologi.

Lingkungan industri merupakan tingkatan dari lingkungan eksternal organisasi yang menghasilkan komponen-komponen yang secara normal memiliki implikasi yang relative lebih spesifik dan langsung terhadap operasional perusahaan. Porter (1991) menyebutkan adanya lima kekuatan dalam persaingan di lingkungan industri, yaitu: (1) Masuknya pendatang baru, (2) Ancaman produk pengganti, (3) Kekuatan tawar-menawar pembeli, (4) Kekuatan tawar-menawar pemasok, dan (5) Persaingan diantara para pesaing yang ada.

Analisis SWOT merupakan akronim dari Strength (kekuatan) dan Weakness (kelemahan) internal dari suatu perusahaan serta Opportunity (peluang) dan Threat (ancaman) lingkungan yang dihadapinya. Kotler (2008) analisis SWOT diartikan sebagai evaluasi terhadap keseluruhan kekuatan, kelemahan, peluang, dan ancaman. Rangkuti (2009) menyatakan SWOT adalah identitas berbagai faktor secara sistem untuk merumuskan strategi.

Menurut David (1998), matriks SWOT merupakan alat pencocokan yang penting dan membantu manajer mengembangkan empat tipe strategi, dimana matriks ini dapat menggambarkan secara jelas bagaimana peluang dan ancaman eksternal yang dihadapi perusahaan dapat disesuaikan dengan kekuatan dan kelemahan yang dimilikinya.

Berdasarkan uraian diatas, dapat disimpulkan analisis SWOT merupakan suatu teknik yang digunakan oleh manajemen untuk melakukan penyorotan yang cepat atas situasi strategis perusahaan

Matriks Internal Factor Evaluation (IFE). Umar (2003) menyebutkan bahwa matriks IFE digunakan untuk mengetahui faktor-faktor internal perusahaan berkaitan dengan kekuatan dan kelemahan yang dianggap penting. Data dan informasi aspek internal dari beberapa fungsional perusahaan, misalnya dari aspek manajemen, keuangan, sumberdaya manusia, pemasaran, sistem informasi, dan produksi/operasi. 
Matriks Eksternal Factor Evaluation (EFE) Umar (2003) menyebutkan pula bahwa matrik EFE digunakan untuk mengevaluasi faktor -faktor eksternal perusahaan. Data eksternal dikumpulkan untuk menganalisis hal-hal yang menyangkut persoalan ekonomi, sosial, budaya, demografi, politik, pemerintahan, hukum, teknologi, persaingan di pasar industri dimana perusahaan berada, serta data eksternal relevan lainnya. Hal ini penting karena faktor eksternal berpengaruh secara langsung maupun tidak langsung terhadap perusahaan.

Matriks Evaluasi Posisi dan Tindakan Strategis (SPACE). Matriks ini adalah alat penting lain dalam pencocokan, alat manajemen strategis ini berfokus pada perumusan strategi terutama yang terkait dengan posisi kompetitif perusahaan. Pendekatan analisa SPACE berusaha untuk mengatasi keterbatasan metode metode lainnya, dengan menambahkan dua dimensi lagi pada matriks. Setiap dimensi dilihat sebagai gabungan dari beberapa faktor yang dievaluasi secara terpisah. Dengan memasukkan sejumlah faktor, manajer dapat melakukan evaluasi alternatif strategi tertentu dari beberapa perspektif, dalam posisi yang lebih baik untuk menentukan strategi yang dipilih.

David (2009) menyebutkan analisa SPACE terdiri dari empat input variabel atau dimensi yang digunakan yaitu:

a. Kekuatan Finansial (Financial Strength)

b. Kekuatan Industri (Industry Strength)

c. Keunggulan Bersaing (Competitive Advantage)

d. Kestabilan Lingkungan (Environment Stability)

Matrik Grand Strategy merupakan tahapan pencocokan (matching stage) pada proses formulasi strategi. Matrik ini didasarkan pada dua dimensi evaluasi yaitu posisi kompetitif (Competititive position) dan pertumbuhan pasar (market growth). Strategi yang sesuai untuk dipertimbangkan suatu organisasi terdapat pada urutan daya tariknya dalam masing-masing kuadran dalam matriks (David, 2009)

Matrik Grand Strategy mempunyai empat kuadran yang mewakili keadaan suatu perusahaan. Pada Kuadran I mewakili perusahaan dengan pertumbuhan pasar yang tinggi dan posisi kompetitif yang kuat. Perusahaan pada kuadran ini mempunyai posisi yang sangat bagus. Untuk perusahaan ini, terus berkonsentrasi pada pasar saat ini (penetrasi pasar dan pengembangan pasar) dan produk saat ini (pengembangan produk) adalah strategi yang sesuai.

Perusahaan pada Kuadran II perlu mengevaluasi pendekatan mereka saat ini terhadap pasar secara serius. Walaupun industri mereka bertumbuh, mereka tidak mampu untuk bersaing secara efektif, dan mereka perlu menentukan, mengapa pendekatan perusahaan saat ini tidak efektif dan bagaimana perusahaan dapat berubah dengan cara terbaik untuk memperbaiki daya saingnya. Karena perusahaan pada Kuadran II berada pada industri yang pasarnya tumbuh secara cepat, strategi intensif (bukannya integrative atau diversifikasi) biasanya menjadi pilihan pertama yang dipikirkan.

Perusahaan yang berada pasa Kuadran III bersaing dalam industri yang tumbuh dengan lambat dan memiliki posisi kompetitif yang lemah. Perusahaan-perusahaan ini harus membuat perubahan drastis untuk menghindari penurunan yang lebih jauh dan kemungkinan likuidasi. Pengurangan asset dan biaya secara ekstensif (retrenchment) harus dilakukan terlebih dahulu. Untuk Kuadran IV, perusahaan memiliki posisi kompetitif yang kuat dalam industri yang tumbuh lambat. Perusahaan ini memiliki kekuatan untuk memperkenalkan program yang terdiverifikasi ke area yang pertumbuhannya menjanjikan.

Analisis Matrix QSPM (Quantitative Strategic Planning Matrix). Selain membuat peringkat strategi untuk memperoleh daftar prioritas, QSPM juga dirancang untuk menetapkan daya tarik relatif dan tindakan alternatif yang layak (David, 1998). Secara sasaran matriks ini menunjukkan alternatif strategi mana yang terbaik untuk 
diimplementasikan terlebih dahulu dari beberapa alternatif strategi yang ada. QSPM menggunakan input dari analisis tahap 1 yaitu EFE dan IFE serta dari hasil mencocokkan analisis tahap 2 untuk memutuskan secara sasaran diantara alternative strategi, artinya matriks IE dan SWOT yang menyusun tahap 2 menyediakan informasi yang diperlukan untuk menetapkan QSPM (tahap 3). QSPM adalah alat strategi untuk mengevaluasi strategi alternatif secara obyektif, berdasarkan pada faktor -faktor kritis untuk sukses eksternal dan internal yang dikenali sebelumnya, dalam penilaiannya memerlukan intuitif yang baik.

METODE

Pengumpulan data. Teknik pengumpulan data yang diperlukan dalam penelitian ini, penulis menggunakan sumber data primer (wawancara dan observasi) dan data sekunder (studi kasus dan kepustakaan).

Metode Analisis. Tujuan yang ingin dicapai penulis adalah memahami, mengevaluasi serta memberikan rekomendasi-rekomendasi strategis kepada perusahaan. Tahap pertama yang akan dilakukan dalam penelitilian ini adalah tahap masukan (Input Stage), dilanjutkan dengan tahap pencocokan (Matching Stage), dan tahap yang terakhir adalah tahap analisis keputusan (Decision Stage).

Tahap input adalah tahapan pengumpulan informasi untuk merumuskan strategi. Di dalam tahapan ini akan dilakukan identifikasi terhadap faktor internal maupun external yang akan menjadi kekuatan (strength), kelemahan (weakness), kesempatan (opportunity) dan ancaman (threat) yang hubungannnya dengan posisi strategis perusahaan.

Tahap pencocokan, dalam tahapan ini teknik yang digunakan teknik analisis dengan menggunakan matriks SWOT (Strength, Weakness, Opportunity, Threat), matriks SPACE (Strategic Position and Action Evaluation Matrix) dan analisis Grand Strategy Matrix.

Tahap keputusan merupakan tahapan terakhir dalam formulasi strategi, dengan cara menetapkan alternatif strategi dimana perusahaan menetapkan strategi yang baik untuk terlebih dahulu dilaksanakan. Alat yang digunakan pada tahapan ini adalah dengan menggunakan QSPM (Quanitatif Strategic Planning Matrix)

\section{HASIL DAN PEMBAHASAN}

Hasil Analisis IFE dan EFE. Total weight skor pda IFE Matrix adalah 2.79 yang berarti Perusahaan Inspeksi berada pada rating sedikit di atas rata-rata 2.50. Dapat dikatakan pula bahwa Perusahaan Inspeksi memiliki kekuatan internal yang lebih besar dibandingkan dengan kelemahannya.

Total weight skor pada EFE Matrix adalah 2.94 yang berarti Perusahaan Inspeksi berada pada rating sedikit di atas rata-rata 2.5 dan menunjukan peluang (opportunities) sudah dimanfaatkan dengan baik dan ancaman pada Perusahaan Inspeksi sudah bisa diantisipasi dengan baik. 


\section{Hasil Analisis SWOT}

\section{Tabel 1. Analisis SWOT}

\section{Kekuatan}

1. Perusahaan Inspeksi merupakan brand internasional yang diakui di dunia.

2. Memiliki kantor cabang hampir di 800 lokasi di seluruh dunia

3. Memiliki pengalaman dibidang inspeksi secara global maupun lokal.

4. Kompetesi lokal dalam bidang jasa inspeksi teknis.

5. Inspektor memiliki sertifikasi internasional.

6. Memiliki spesialisasi kemampuan untuk dua jasa advance NonDestructive Test (NDT).

7. Dilakukannya pengembangan dan pelatihan rutin

\section{Kelemahan}

1. Keterbatasan beberapa peralatan berteknologi tinggi.

2. Kemungkinan peminjaman alat kepada legal entity perusahaan inspeksi yang berada di negara tetangga menyebabkan proses delivery yang cukup memakan waktu.

3. Persaingan harga yang cukup sengit dengan perusahaan dalam negeri untuk jasa inspeksi teknis.

4. Keterbatasan dalam memaksimalkan tingkat komponen dalam negeri (TKDN).

5. Belum memiliki warehouse untuk penyimpanan peralatan teknis.

6. Belum tersedianya tenaga kerja proposal engineer yang paham dalam peraturan tender PTK 007

7. Tidak memiliki cabang atau kantor perwakilan di daerah-daerah potensial

\section{Ancaman}

1. Negative Investment List untuk perusahaan asing dalam bidang jasa inpeksi.

2. Perusahaan Minyak dan Gas melakukan efisiensi.

3. Mata uang rupiah yang terus melemah terhadap mata uang Euro.

4. Merger yang dilakukan oleh sesama perusahaan jasa inpeksi milik pemerintah.

5. Peraturan pengadaan barang dan jasa di sektor Migas yang diatur oleh PTK 007 mengenai pemuka konsorsium dalam setiap tender adalah perusahaan dalam negeri.

\begin{abstract}
mengimplemantasikan Asset Integrity Managements (AIMs) pada setiap plantnya.
\end{abstract}

5. Tingginya awareness terhadap safety di lingkungan kerja

Berdasarkan analisis strategi perusahaan pada tahap matching stage, maka dibuat rangkuman yang terdiri dari Analisis Matrix SWOT, SPACE, dan Grand Strategy.

Tabel 2. Rangkuman Analisis Matrix SWOT, SPACE, dan Grand Strategy

\begin{tabular}{|l|l|l|l|}
\hline Strategi Alternatif & SWOT & SPACE & Grand Strategy \\
\hline
\end{tabular}




\begin{tabular}{|l|l|l|l|}
\hline \hline Integrasi ke depan & $\mathrm{X}$ & & \\
\hline Integrasi ke belakang & & & $\mathrm{X}$ \\
\hline Integrasi Horizontal & $\mathrm{X}$ & $\mathrm{X}$ & $\mathrm{X}$ \\
\hline Penetrasi Pasar & & $\mathrm{X}$ & \\
\hline Pengembangan Pasar & $\mathrm{X}$ & $\mathrm{X}$ & $\mathrm{X}$ \\
\hline Pengembangan Produk & $\mathrm{X}$ & $\mathrm{X}$ & $\mathrm{X}$ \\
\hline Diversifikasi Terkait & & & \\
\hline Diversifikasi tidak terkait & & & \\
\hline Joint Venture & & & \\
\hline Penciutan & & & \\
\hline Divestasi & & & \\
\hline Likuidasi & & & \\
\hline
\end{tabular}

Hasil Matrix QSPM (Quantitative Strategic Planning Matrix). Dari hasil matrix QSPM di atas, diketahui nilai untuk total keseluruhan TAS pengembangan produk paling tinggi yaitu sebesar 5.59, dibandingkan dengan integrasi horizontal sebesar 5.43 dan pengembangan pasar sebesar 5.29. Jadi strategi yang direkomendasikan Perusahaan Inspeksi adalah pengembangan produk. Perusahaan Inspeksi perlu fokus terhadap pengembangan produk dan melihat trend pasar akan kebutuhan tertentu di masa sekarang. Sehingga variasi yang disebabkan oleh pengembangan produk dapat memperkecil resiko karena lini produk yang meningkat.

Rekomendasi strategi kedua yang tidak kalah penting adalah integrasi horizontal sebesar 5.43. Perusahaan Inspeksi diharapkan untuk bisa melakukan identifikasi dan mengevaluasi lebih lanjut mengenai kemungkinan untuk melakukan konsorsium, merger ataupun Joint Venture. Mengingat industry Migas adalah industri yang penuh dengan regulasi maka sebagai perusahaan dengan penanaman modal asing diharapkan bisa melakukan kolaborasi dengan perusahaan lokal di Indonesia untuk menambah akses kedalam industri migas khususnya inspeksi statutori maupun voluntari untuk meningkatkan kesempatan dalam berpartisipasi di tender-tender besar di industri migas.

\section{PENUTUP}

Simpulan. Berdasarkan hasil wawancara, forum group discussion, dan melakukan analisis strategi, strategi yang direkomendasikan untuk Perusahaan Inspeksi adalah dengan melakukan pengembangan produk serta mulai mengidentifikasi dan mengevaluasi untuk melakukan kolaborasi dengan perusahaan lokal melalui konsorsium atau joint venture. Pengembangan produk yang dapat dilakukan adalah dengan mengembangkan dua jasa yang sedang dibutuhkan pasar saat ini yaitu Asset Intergity Management dan Risk Based Inspection. Dengan memiliki pengalaman dan kualifikasi yang ada di kantor pusat dalam bidang tersebut maka Perusahaan Inspeksi memiliki dukungan yang cukup kuat untuk mengembangkan kedua jasa tersebut di industri migas di Indonesia.

Perusahaan juga direkomendasikan untuk melakukan kolaborasi dengan perusahaan lokal di Indonesia guna untuk meningkatkan aksesibilitas dalam berpartisipasi dalam tender, meningkatkan tingkat komponen dalam negeri (TKDN), dan meningkatkan aksesibilitas dalam bisnis jasa inspeksi statutori.

Saran. Hasil penelitian ini diharapka dapat memberikan saran kepada pihak perusahaan untuk memperhatikan strategi bisnis yang tepat serta secara aktif berpatisipasi dan menjadi anggota dalam asosiasi yang behubungan dengan industri inspeksi. Untuk dapat mengembangan bisnisnya bisa dengan membuka representative office di area potensial untuk aktifitas petrokimia seperti Merak, Cilegon, Pekanbaru, Balikpapan, dan Palembang. Selain itu agar dapat memanfaatkan kompetensi atau kualifikasi yang dimiliki oleh kantor pusat dengan mulai mengembangkannya di Indonesia. Dimasa yang akan datang untuk dapat meningkatkan penelitian ini ke jenjang yang lebih tinggi sehingga dapat dilakukan analisis lebih mendalam terkait Perusahaan Inspeksi 


\section{DAFTAR RUJUKAN}

David, Fred R. 1998, Strategic Market Management. Terjemahan. Gramedia, Jakarta.

David, Fred R. 2002, Manajemen Strategis Versi Bahasa Indonesia, Edisi Ketujuh, PT Prenhallindo, Jakarta.

David, Fred R. 2011, Strategic Management Concept and Cases (13rd ed), New York: Pearson Education

Fred R. David, 2009, Manajemen Strategis. Salemba Empat Jakarta.

Grant, Robert M. 1999. Analisis Strategi Kontemporer, Konsep, Teknik, Aplikasi. Edisi Kedua. Jakarta: Erlangga.

Hunger, J David dan Thomas L Wheelen. 2003. Management Strategis. Terjemahan Julianto Agung. Edisi 2, Andi.Yogyakarta.

Husein Umar. (2001). Metode Penelitian dan Aplikasi Pemasaran. Jakarta: PT Gramedia Pustaka Utama

Kotler, Philip. 2005. Manajamen Pemasaran, Jilid 1 dan 2. Jakarta: PT. Indeks Kelompok Gramedia

Pearce, John A. dan Robinson, Richard B. 1997, Manajemen Strategik, Formulasi Implementasi dan Pengendalian. Terjemahan. Jilid Kesatu, Binarupa Aksara, Jakarta.

Pearce, John A. dan Robinson, Richard B. 2014, Manajemen Strategis: Formulasi Implementasi dan Pengendalian. Terjemahan. Jilid Kedua, Salemba Empat, Jakarta

Porter, Michael E. 1991, Strategi Bersaing: Teknik Menganalisis Industri dan Pesaing, Penerbit Erlangga, Jakarta Selatan.

Porter Michael E. 1992. Strategi Bersaing. Maulana Agus, Penerjemah; Hutauruk Gunawan, Editor. Jakarta: PT. Gelora Aksara Pratama. Terjemahan dari: Competitive Strategy.

Rangkuti, F. 2000. Analisis SWOT Teknik Membedah Kasus Bisnis. Gramedia Pustaka Utama. Jakarta.

Tjen Tha. 2015. PJIT dan sebuah visi. Diambil dari http://www.kompasiana.com/tjentha/pjitdan-sebuah visi_55f642ad3f23bdc12a8c549c

PERUSAHAAN INSPEKSI. 2016. PERUSAHAAN INSPEKSI at a glance. Diambil dari http://www.tuv-sud.com 
